\title{
PHOSPHORUS AND IRON IN SAGITTA SETOSA AND SAGITTA ELEGANS
}

\author{
By R. J. Harrison \\ Gonville and Caius College, Cambridge
}

(Text-fig. I)

Cooper (1939) reported much more iron in Sagitta setosa than in S. elegans. The analyses had been made in different years, while for $S$. setosa only one sample had been examined and this may conceivably have been contaminated. In the spring of 1939 the problem was accordingly attacked afresh.

\section{Methods}

To reduce the likelihood of contamination, the galvanized iron bucket of the ring trawl was replaced by a glass breffit from which the animals were removed by a glass pipette on to a filter paper; from this they were transferred by a glass seeker to a tared micro-beaker. Each sample was dried overnight in an aluminium-lined electric oven at $110^{\circ} \mathrm{C}$. After weighing, concentrated sulphuric acid (0.I ml.) was added, and the mixture heated at $\mathrm{I} 20^{\circ} \mathrm{C}$. for I hr in a hot-air bath made from a fire-clay crucible. The carbonaceous residue was oxidized with Merck's perhydrol which was found to contain a negligible amount of phosphorus and no iron; three to four drops were sufficient. The solution was then made up to $25 \mathrm{ml}$.

The method used for estimating the phosphorus was similar to that used by Cooper (1934) except that the addition of the stannous chloride followed that of the acid molybdate reagent.

The iron was estimated by the $2: 2^{\prime}$-dipyridyl method (Cooper, 1935). Economy of this rather expensive reagent was achieved without loss of accuracy by the following procedure. Ten $\mathrm{ml}$. of sample were treated with $0.1 \mathrm{ml} .4 \mathrm{~N}$ hydrochloric acid and $0.2 \mathrm{ml}$. I0 \% sodium sulphite as reducing agent. After I hr $0.5 \mathrm{ml}$. of a $0.2 \%$ solution of dipyridyl in $\mathrm{N} / 50$ hydrochloric acid together with $0.4 \mathrm{ml}$. of a IoN solution of ammonium acetate were added. Four hours later the samples were compared with a standard $(3.75 \mu \mathrm{g}$. Fe in $\mathrm{ro}$ ml. water) in a Kober colorimeter.

Table I shows that there was a gradual decrease in the amount of iron in S. setosa until February 24. During this period the Sagitta were all immature, being mostly in stage II (see Russell, 1932, p. I33). In March the iron content was still somewhat low, but in April it had risen almost to that of the first sample. In the samples taken in March and April the Sagitta were more mature. 


\section{TABLE I}

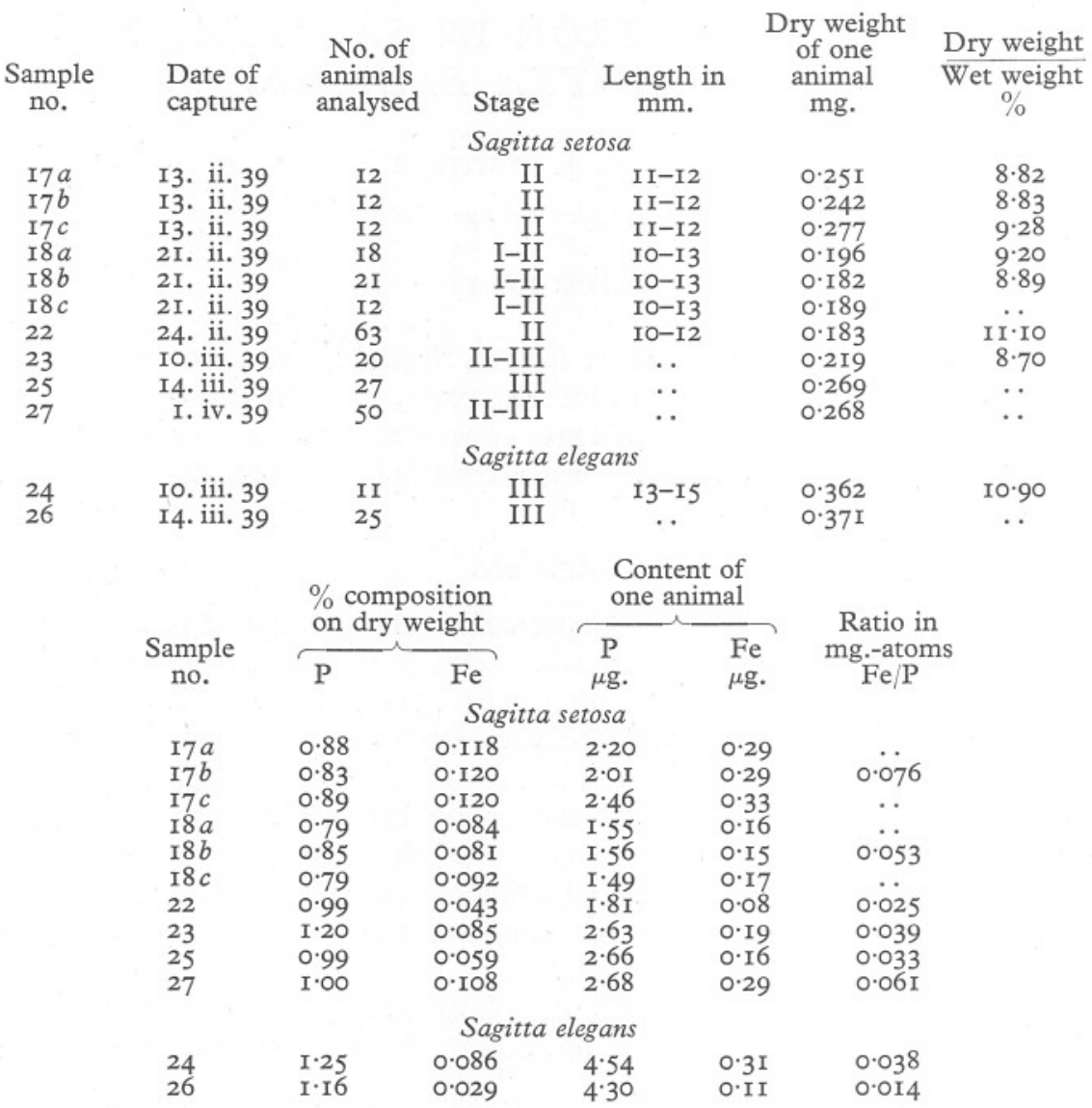

The numbers of $S$. setosa caught in half-hour oblique trawls with the $2 \mathrm{~m}$. stramin ring trawl over the period of the observations are given below. These figures were kindly given me by $\mathrm{Mr} \mathrm{F}$. S. Russell.

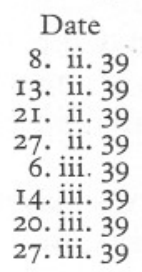

Numbers of $S$. setosa

$$
\begin{array}{r}
9620 \\
8030 \\
571 \\
199 \\
22 \\
91 \\
3 \\
\ldots
\end{array}
$$

It is noteworthy that the numbers of Sagitta decreased very considerably towards the end of February. This decrease was probably due to the dying off of the brood that had lived over the winter. 
Fig. I shows the logarithms of the numbers of $S$. setosa in the ring trawl hauls and the ratios $\mathrm{Fe} / \mathrm{P}$ plotted against time. This figure and Table I show clearly that as the numbers of $S$. setosa decreased, the content of iron, both absolutely and relatively to phosphorus, also fell away. Finally only a few individuals of higher iron content were found.

The sequence of generations in the life cycle of $S$. setosa is not clear (Russell, I933), but it is possible that by April individuals of a different generation from that in February are prevalent. If this be so it is perhaps significant that in April the iron content was high. It is not possible to draw definite con-

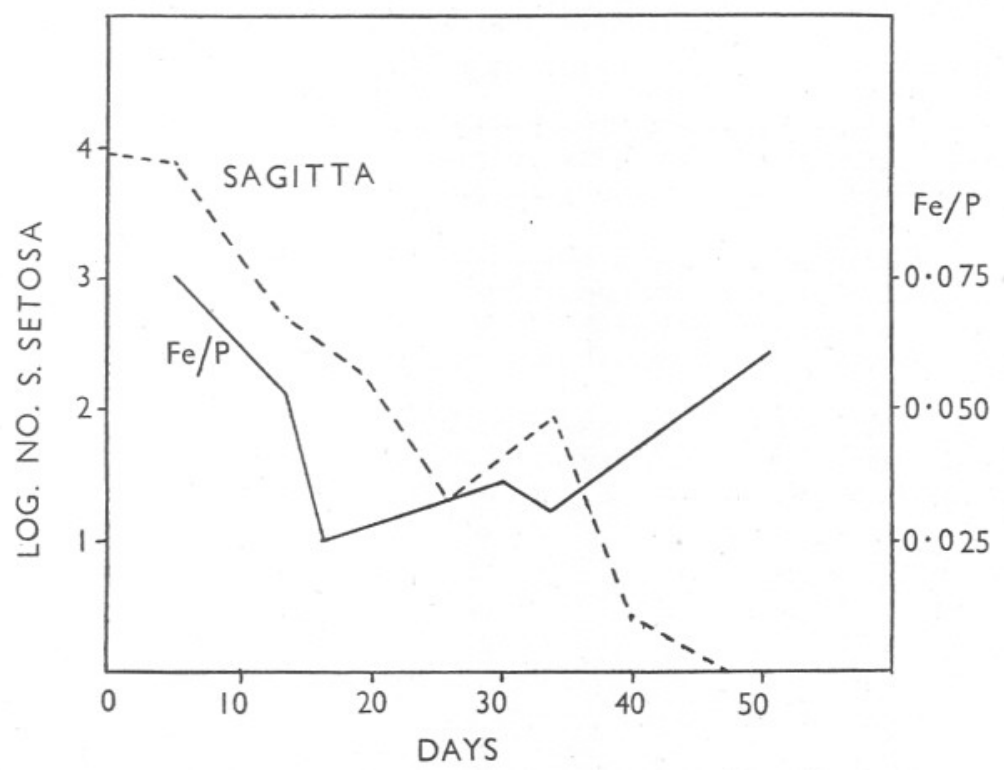

Fig. I. Numbers of Sagitta setosa in ring trawl catches plotted logarithmically (- - ); and ratio of iron to phosphorus in mg.-atoms (-- ), during the period of observations.

clusions from the results, but the decrease in iron content during the period of dying off of the February population may perhaps suggest that the viability of Sagitta is associated with their content of iron. At any rate we have definite indications that the iron content may vary considerably from time to time and that, therefore, the problem is well worth following throughout the successive generations of Sagitta during a year.

$S$. elegans was scarce during the whole period of the investigation, but the only two samples with sufficient numbers for analysis showed a considerable decrease in iron content between March Io and I4.

The high iron content found by Cooper in S. setosa in May I934 has not yet been reproduced, the amount of iron appearing to be of the same order in the two species. 
My thanks are due to Mr F. S. Russell, F.R.S., for suggesting the problem and for assistance in the sampling and to Dr L. H. N. Cooper for much helpful advice on the chemical technique.

\section{SUMMARY}

The amount of iron and phosphorus in Sagitta setosa and S. elegans has been estimated. As the winter population decreased in numbers the iron content per animal also decreased, rising again in what may have been the next brood.

\section{REFERENCES}

COOPER, L. H. N., I934. The determination of phosphorus and nitrogen in plankton. Fourn. Mar. Biol. Assoc., Vol. xIx, pp. 755-60.

- I935. Iron in the sea and in marine plankton. Proc. Roy. Soc. B, Vol. CxviII, pp. 419-38.

1939. Phosphorus, nitrogen, iron and manganese in marine zooplankton. Fourn. Mar. Biol. Assoc., Vol. xxiII, pp. 387-90.

Russell, F. S., I932. On the biology of Sagitta. The breeding and growth of Sagitta elegans Verrill in the Plymouth area, I930-31. Fourn. Mar. Biol. Assoc., Vol. XVIII, pp. I3I-46.

- I933. On the biology of Sagitta. III. A further observation on the growth and breeding of Sagitta setosa Verrill in the Plymouth area. Fourn. Mar. Biol. Assoc. Vol. xviII, pp. 555-8. 